\title{
The Astrocytic Response to Afferent Activity Blockade in Chick Nucleus Magnocellularis Is Independent of Synaptic Activation, Age, and Neuronal Survival
}

\author{
Karen S. Canady, Richard L. Hyson, ${ }^{a}$ and Edwin W Rubel \\ Virginia Merrill Bloedel Hearing Research Center and Department of Otolaryngology-Head and Neck Surgery, \\ University of Washington, Seattle, Washington 98195
}

\begin{abstract}
Astrocytes in nucleus magnocellularis (NM) of the chick respond to afferent activity blockade with increased immunoreactivity for glial fibrillary acidic protein (GFAP). NM neurons respond to the same manipulations with reduced protein synthesis, ribosomal dissociation, and subsequent death of a subset of these neurons. In the present study, we sought to evaluate the relationship between these neuronal and glial responses and to determine if similar activity-dependent mechanisms mediate them. We first examined the anatomical relationship between NM neurons and astrocytic processes by electron microscopy and GFAP immunostaining. Both methods showed that NM neurons deprived of activity for $6 \mathrm{hr}$ were apposed by more glial processes than active NM neurons. However, we found no preferential positioning of GFAP-immunoreactive processes near neurons of the dying or surviving populations, and there were no differences in glial process apposition to dying versus surviving neurons at the EM level.
\end{abstract}

To determine whether the astrocytic response is similar to the neuronal response in age dependence, GFAP immunoreactivity was analyzed in adult chickens following unilateral afferent activity blockade. Unlike the neuronal response to activity blockade, the astrocytic response is equally strong in adult animals. These results imply an independence of the neuronal and astrocytic responses to activity blockade, raising the possibility that these two cell types may be responding to different activity-related signals. This possibility was tested using an in vitro slice preparation. Unilateral stimulation of NM was provided in three ways: orthodromically, antidromically, and orthodromically in a lowcalcium medium. The regulation of astrocytic GFAP immunoreactivity by these manipulations of activity was then analyzed. The results of these experiments show that, unlike neuronal protein synthesis, astrocytic GFAP immunoreactivity can be suppressed by either presynaptic or postsynaptic

\footnotetext{
Received Dec. 27, 1993; revised Mar. 28, 1994; accepted Apr. 6, 1994.

We gratefully acknowledge the assistance of Dale Cunningham with electron microscopy, and both Glen MacDonald and Dr. JiaLin Shang with data analysis. Dr. Diana I. Lurie provided helpful comments on an earlier version of the manuscript. This work was supported by PHS Grants DC 00520 and DC 00018 to E.W R. and DC 00858 to R.L.H.

Correspondence should be addressed to Edwin W Rubel, Virginia Merrill Bloedel Hearing Research Center, RL-30, University of Washington, Seattle, WA 98195 .

a Present address: Department of Psychology, Florida State University, Tallahassee, FL 32036-1051.

Copyright (C) 1994 Society for Neuroscience $0270-6474 / 94 / 145973-13 \$ 05.00 / 0$
}

neuronal activity. Therefore, the astrocytes and neurons are regulated by different activity-dependent signals and, by the present measures, their responses to activity blockade appear independent of one another.

[Key words: astrocytes, glial fibrillary acidic protein, protein synthesis, in vitro slice, development, neuronal death, gliosis, autoradiography, immunocytochemistry, leucine incorporation]

The effects of reduced afferent input and deafferentation on neural structures have been studied in a variety of sensory systems (Globus, 1975; Reh and Constantine-Paton, 1985; Stryker and Harris, 1986; Rubel et al., 1990). These manipulations often result in neuronal atrophy and the formation of reactive glial processes. Some investigators consider the reactive glial cells to be involved in the clearance of debris resulting from neuronal degeneration (Reier, 1986). Other data suggest that glial cells may provide trophic agents to support damaged neurons (Banker, 1980; Manthorpe et al., 1986; Brenneman et al., 1987). While both neuronal atrophy and glial reactions have been reported following deafferentation, few studies have described the relationship between reactive glial processes and individual deafferented neurons (Wong-Riley, 1972; Meshul et al., 1987).

Previous work in our laboratory has documented the effects of blocking excitatory input on the neurons and glia of nucleus magnocellularis (NM) in chickens (reviewed by Rubel et al., 1990). Since NM receives its only excitatory input via eighth nerve fibers arising from the ipsilateral basilar papilla (avian cochlea), removal of the cochlea, or intraperilymphatic injection of tetrodotoxin (TTX), results in the cessation of action potentials in the auditory portion of the eighth nerve and in NM (Born et al., 1991). Activity in the contralateral NM is not altered by these manipulations, providing a within-animal and withintissue section control.

One effect of deafferentation on NM is the death of $25-30 \%$ of its neurons. This neuronal loss occurs within $3 \mathrm{~d}$ of cochlea removal (Born and Rubel, 1985). Prior to their death, these neurons show a loss of staining for Nissl substance and stop synthesizing proteins. The neurons that have stopped synthesizing proteins can be identified by their failure to incorporate tritiated leucine as soon as $6 \mathrm{hr}$ after cochlea removal (Steward and Rubel, 1985), by complete dissociation of ribosomes (Rubel et al., 1992), and by loss of immunoreactivity for an antibody directed against ribosomal RNA (Garden et al., 1994). These are the same $25-30 \%$ of NM neurons that will eventually die if afferent activity is not restored. The morphological features of 
this subpopulation correspond closely with a form of apoptosis (Clarke, 1990; Garden et al., 1994).

Another rapid effect of cochlea removal on NM is increased staining for GFAP and increases in the number of glial processes. Within 4-6 hr of cochlea removal, the immunoreactivity for GFAP increases by $80-100 \%$ and the total length of silverimpregnated glial processes increases by approximately $110 \%$ (Rubel and MacDonald, 1992). Both the glial and the neuronal responses to cochlea removal have been replicated by blocking eighth nerve action potentials with intralabyrinthine tetrodotoxin, and both of these responses are reversed by the resumption of neuronal activity (Born and Rubel, 1988; Canady and Rubel, 1992). Recently, several other laboratories have reported rapid changes in glial processes as well as GFAP or its mRNA following manipulations intended to alter neuronal activity (Steward et al., 1991; Canady et al., 1992; Georgiou et al., 1993; I Iawrylak et al., 1993).

Since both the neuronal and glial changes in NM occur within hours of cochlea removal, it is of interest to learn if any relationship might exist between these two events. For example, one might hypothesize that glial processes are attracted to dying neurons or perhaps contribute to neuronal death. This might result in more GFAP-immunoreactive processes located near the apoptotic neurons that have ceased protein synthesis and show degraded ribosomes, compared to adjacent neurons. A second hypothesis would be that glial processes contribute to neuronal survival in the face of challenge. In this case, glial processes might be preferentially located near those neurons that will survive deafferentation. Third, one could hypothesize that the neuronal and glial responses to activity blockade are unrelated and expect that the glial processes are distributed randomly with respect to the dying and surviving neurons. We tested these hypotheses in two ways: (1) by double labeling tissue from chicks surviving $6 \mathrm{hr}$ after cochlea removal for ${ }^{3} \mathrm{H}$-leucine and GFAP, and (2) by comparing the relative amount of the neuronal soma membrane apposed by glial processes between apoptotic NM neurons and adjacent neurons as well as NM neurons on the opposite side of the brainstem. Both analyses replicated earlier results, showing an increase in glial processes surrounding activity-deprived neurons, but there were no differences in the extent of glial processes surrounding NM neurons undergoing apoptosis and those destined to survive deafferentation.

The apparent independence of the glial and neuronal responses to activity blockade suggest that there may be conditions under which only one of these two cell types would respond. Born and Rubel (1985) reported little or no neuronal death or shrinkage in adult chickens, and Steward and Rubel (1985) reported that adult chickens do not show reduced protein synthesis in NM neurons following cochlea removal. In contrast to the age dependence of neuronal changes, we report here that the increase in astrocytic GFAP immunoreactivity does occur in NM of adult chickens following cochlea removal or blockade of eighth nerve activity with TTX.

To investigate further the independence of rapid neuronal and glial responses to activity deprivation, we replicated the in vitro paradigm used by Hyson and Rubel (1989) to study afferent regulation of neuronal protein synthesis in NM. These investigations demonstrated that maintenance of protein synthesis by NM neurons requires the postsynaptic action of a trophic substance released from active eighth nerve terminals. Direct electrical activation of NM neurons, via antidromic stimulation of their axons and stimulation of eighth nerve axons without transmitter release, are not sufficient to upregulate neuronal protein synthesis. In the present study, we report that the glial response is regulated by different signals than those involved in the regulation of NM neurons. Specifically, any local neuronal activity, be it presynaptic activity alone, postsynaptic alone, or both, will prevent the increase in GFAP immunoreactivity.

\section{Materials and Methods}

\section{Subjects and anesthesia}

The subjects were white leghorn chickens. Eggs were obtained from a local supplier (H\&N, Redmond, WA) and incubated and hatched in the University of Washington vivarium in AAALAC-approved facilities. Animals were given free access to food and water at all times. Except where otherwise noted, hatchlings, 1-3 weeks of age, were used. Nine adult chickens were obtained directly from the supplier and used at 68 weeks of age.

Prior to surgery or perfusion, chickens were anesthetized with an intramuscular injection of ketamine $(80 \mathrm{mg} / \mathrm{kg}$ body weight) followed by either sodium pentobarbital $(15 \mathrm{mg} / \mathrm{kg}$ body weight) or Equithesin $(1.5 \mathrm{ml} / \mathrm{kg})$ injected intraperitoneally. Equithesin $(9.8 \mathrm{mg} / \mathrm{ml}$ sodium pentobarbital, $42.5 \mathrm{mg} / \mathrm{ml}$ chloral hydrate, $21.3 \mathrm{mg} / \mathrm{ml}$ magnesium sulfate, in $12 \%$ ethanol, $44 \%$ propylene glycol) was used for adult chickens.

\section{Activity blockade in vivo}

Cochlea removal. This procedure is described in detail by Born and Rubel (1985). Nine hatchlings were anesthetized and the down surrounding the ear canal was removed with a depilatory. Access to the middle ear was facilitated by trimming the tuft of feathers covering the canal and by cauterizing the canal to enlarge it. A pair of fine forceps was used to tear the tympanic membrane and remove the columella (middle ear ossicle). The cochlea was then extracted through the oval window. The middle ear was packed with Gelfoam soaked in antiseptic, and the canal was sealed with cyanoacrylate glue. Hatchlings were allowed to survive $6 \mathrm{hr}$ after cochlea removal. For adult chickens, suction was applied to dehydrate the oval window region and the cochlea was removed with the bent tip of a 23 gauge needle rather than with forceps. Adult chickens were sacrificed $3 \mathrm{hr}$ after cochlear removal. In all cases, the completeness of cochlea removal was assured by floating the removed tissue in a petri dish and examining it under the operating microscope.

$T T X$ injection. The procedure for adult chickens is a modification of the method described for hatchlings by Canady and Rubel (1992). A 1 $\mathrm{cm}$ incision was made posterior to the ear canal and oriented toward the vertex. A drill was used to remove a region of spongy temporal bone, exposing the smooth, thin bone overlying the vestibule. A 0.5 $\mathrm{mm}$-diameter hole was drilled in this smooth bone, providing access to the perilymph of the inner ear. Five microliters of $0.3 \mathrm{mM}$ TTX (Sigma Chemical, St. Louis, MO) were injected into the perilymph. The hole was sealed with bone wax and the region was packed with Gelfoam soaked in antiseptic prior to suturing the skin. Adult chickens were sacrificed $3 \mathrm{hr}$ following either cochlea removal $(n=3)$ or TTX injection $(n=6)$.

General histology. Subjects were deeply anesthetized and perfused transcardially with $0.9 \%$ saline for 1-2 min followed by $4 \%$ paraformaldehyde in phosphate buffer for 10-15 min. The brainstems were dissected, blocked, and immersed in $4 \%$ paraformaldehyde for $12-18$ $\mathrm{hr}$. At this time, the brains were placed in either phosphate-buffered saline (PBS) for 3-6 hr or 30\% sucrose in PBS overnight. The brains in PBS were then sectioned at $30 \mu \mathrm{m}$ on a vibratome. The vibratome sections were floated in 30\% sucrose in PBS in 24-well plastic culture plates. After sinking in the $30 \%$ sucrose solution, the sections were frozen by placing the culture plates on dry ice for $10 \mathrm{~min}$. The sections were then allowed to thaw at $4^{\circ} \mathrm{C}$. The remaining brains, after sinking in $30 \%$ sucrose, were frozen and sectioned at $20 \mu \mathrm{m}$ using a cryostat at $-25^{\circ} \mathrm{C}$ and thaw mounted on chrome-alum-subbed glass slides.

Electron microscopy. Four hatchling chickens were used for electron microscopic analysis of glial processes adjacent to NM neuronal somata. Following unilateral cochlea removal, the birds were allowed to survive for $6 \mathrm{hr}$. They were then given an overdose of sodium pentobarbital and transcardially perfused with PBS followed by mixed aldehydes $(2.0 \%$ paraformaldehyde, $3.0 \%$ glutaraldehyde) in $0.1 \mathrm{~m}$ phosphate buffer at pH 7.4 at room temperature. The head was then immersed in cold fixative overnight. After removing and blocking the brain, $100 \mu \mathrm{m}$ vi- 
bratome sections were cut through NM in the coronal plane. The sections were then hemisected at the midline and the dorsal half of each section was osmicated in $1 \%$ osmium tetroxide in $0.1 \mathrm{M}$ phosphate buffer, dehydrated, and embedded in Spurr's epoxy resin. Thin sections $(\sim 90 \mathrm{~nm})$ were cut from the two halves of the same vibratome section from the midpoint of the rostrocaudal extent of NM. Electron micrographs of 20-30 NM cells from each brain were made at an original magnification of $10,200 \times$ and printed at a final magnification of 25,500 . The cells to be analyzed were chosen at random with the following restrictions: all neurons with dissociated ribosomes in the thin section from the deafferented NM and at least as many (usually more) neurons with intact ribosomes from the same thin section were analyzed. An additional sample of NM neurons from the normal side of the brain, chosen at random, were photographed and analyzed. All NM neurons were photographed so as to include as much of the soma membrane as possible at the designated magnification.

Immunocytochemistry. Cryostat sections were rehydrated in a graded series of ethanols followed by PBS. The tissue sections (thaw mounted or free floating) were then incubated in $4 \%$ normal goat serum for $1 \mathrm{hr}$. This and all other immunocytochemical reagents were prepared in $1 \%$ bovine serum albumin, $0.1 \%$ sodium azide (except the ABC reagent) in PBS. The sections were then incubated in rabbit serum immunized against bovine GFAP (DAKO, Santa Barbara, CA). Cryostat sections were incubated in primary antiserum diluted 1:600-2400 overnight in a humidified chamber at room temperature. Free-floating vibratome sections were incubated in primary antiserum diluted 1:1200-9600 for $2 \mathrm{~d}$ at room temperature on a shaker table. Control sections were incubated in normal rabbit IgG diluted at 1:10,000. Following the incubation in primary antiserum and all subsequent reagents, the sections underwent three $10 \mathrm{~min}$ washes in PBS. The sections were then incubated in biotinylated goat anti-rabbit serum, diluted 1:200, for $2 \mathrm{hr}$, washed, and then incubated in an avidin-biotin complex (Vectastain ABC Kit, Vector Labs, Burlingame, CA). Diaminobenzidine $(0.25 \mathrm{mg} /$ $\mathrm{ml}$; Sigma, St. Louis, MO) with $0.1 \%$ hydrogen peroxide in Tris buffer $\mathrm{pH}$ 7.6, was used as the chromogen. After washing, the free-floating sections were mounted onto poly-L-lysine-coated glass slides. The sections were dehydrated in a graded series of ethanols, cleared in xylenes, and coverslipped using DPX mountant.

Amino acid incorporation. These methods for assessing amino acid incorporation were adapted from those used in previous studies (Steward and Rubel, 1985; Born and Rubel, 1988). The five hatchlings used for double-labeling studies were allowed to survive for $6 \mathrm{hr}$ following cochlea removal. Thirty minutes prior to sacrifice, each chick received an intracardiac injection of $0.5 \mathrm{mCi}{ }^{3} \mathrm{H}$-leucine (New England Nuclear Research Products, Boston, MA; specific activity, $20 \mathrm{Ci} / \mathrm{mmol}$ ). At the end of the $6 \mathrm{hr}$ survival period, the chicks werc ancsthetized and transcardially perfused as described above. The tissue was then frozen and sectioned at $8 \mu \mathrm{m}$ on a cryostat. The tissue was first processed for GFAP immunocytochemistry. After the chromogen reaction was complete, the slides were washed and then dipped in Kodak autoradiographic emulsion. The slides were allowed to dry overnight and then boxed and kep at $4^{\circ} \mathrm{C}$ for 2.5-5 weeks. The slides were developed in Kodak D19 developer, fixed, and washed. The tissue was lightly counterstained with thionin, dehydrated in a graded series of ethanols, cleared in xylenes, and coverslipped.

\section{In vitro slices}

Slice preparation. The procedures for obtaining chick brainstem slices have been described in detail (Hyson and Rubel, 1989). Briefly, chicks were decapitated and the brainstem was dissected free from the cranium. Coronal slices were cut at $300 \mu \mathrm{m}$ on a vibratome. Slices containing bilaterally symmetrical portions of the auditory nerve and NM were then transferred to a recording chamber. Preparation of the slice in this manner took approximately 10-15 min.

General procedures and media. The slice was placed in the recording chamber on a piece of lens paper and held in place by a piece of cotton mesh secured with metal clips. ACSF flowed through the chamber at $3.5 \mathrm{ml} / \mathrm{min}$. The ACSF was oxygenated and warmed prior to inflow. The temperature of the medium as it flowed through the chamber was approximately $34^{\circ} \mathrm{C}$. Standard ACSF consisted of $130 \mathrm{~mm} \mathrm{NaCl}, 3 \mathrm{~mm}$ $\mathrm{KCl}, 2 \mathrm{~mm} \mathrm{CaCl}_{2}, 2 \mathrm{~mm} \mathrm{MgCl}, 26 \mathrm{~mm} \mathrm{NaHCO}_{3}, 1.25 \mathrm{~mm} \mathrm{NaH}_{2} \mathrm{PO}_{4}$, and $10 \mathrm{~mm} d$-glucose. For the low-calcium/high-magnesium experiments, this medium was altered to contain $0.5 \mathrm{~mm} \mathrm{CaCl}_{2}$ and $5 \mathrm{~mm}$ $\mathrm{MgCl}_{2}$ (Hyson and Rubel, 1989).

Orthodromic stimulation. The general procedures are shown sche-

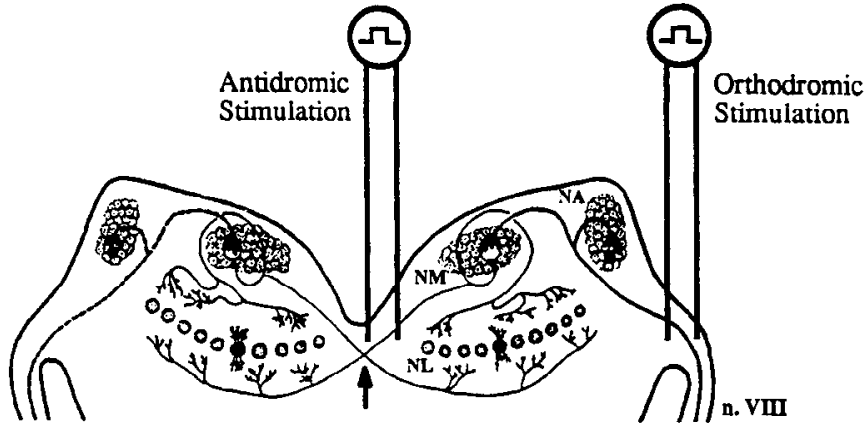

Figure 1. Schematic of the brainstem auditory system of the chick displaying the general stimulation procedures. For unilateral orthodromic stimulation of $\mathrm{NM}$, a stimulating electrode was placed on the auditory nerve $(n . V I I I)$ on one side of the slice. For unilateral antidromic stimulation of NM, the stimulating electrode was placed on the axons of NM neurons near midline in the crossed dorsal cochlear tract. To prevent antidromic stimulation of the contralateral NM, axons were transected at midline (arrow). $N A$, nucleus angularis; $N L$, nucleus laminaris; $N M$ nucleus magnocellularis.

matically in Figure 1. For orthodromic stimulation, a bipolar stimulating electrode (twisted Teflon-coated $\mathrm{Ag}$ wires) was placed on the stump of the anditory nerve on one side of the slice. Slices were unilaterally stimulated at $10 \mathrm{~Hz}$ with $50 \mathrm{~V}, 20 \mu \mathrm{sec}$ pulses for $3 \mathrm{hr}$.

Antidromic stimulation. Antidromic stimulation of NM neurons was achieved by electrically stimulating their axons near midline in the crossed dorsal cochlear tract. In order to limit activation to NM on one side of the slice, a cut was made through this tract at midline. Stimulation parameters were the same as in the orthodromically stimulated slices.

Controls. Control slices were maintained in the recording chamber for $3 \mathrm{hr}$. These slices had a stimulating electrode placed on the auditory nerve (orthodromic control), or were cut at midline and had a stimulating electrode placed on the crossed dorsal cochlear tract (antidromic control), but no stimulation was delivered.

Recording. In each slice, field potentials were monitored to confirm the effectiveness of stimulation. Glass micropipettes filled with ACSF (0.5-5 M $\Omega$ ) were placed on NM. The electrical signals were amplified and displayed on an oscilloscope.

Histology. At the conclusion of an experiment, a notch was made in the ventral surface of one side of the slice so that the stimulated side could be identified later. Each slice was immersion fixed either in $4 \%$ paraformaldehyde for $4 \mathrm{hr}$ or in methacarne fixative for $1 \mathrm{hr}$. Paraformaldehyde-fixed slices were then stored in $30 \%$ sucrose in PBS overnight. From this point on, this tissue was treated similarly to the other frozen-sectioned brainstem tissue immunolabeled for GFAP, except that endogenous peroxidase activity was quenched with $0.03 \% \mathrm{H}_{2} \mathrm{O}_{2}$ in absolute methanol for 20 min prior to immunostaining. Methacarnefixed slices were stored overnight in $70 \%$ ethanol, then embedded in paraffin, sectioned at $10 \mu \mathrm{m}$ and deparaffinized prior to immunostaining.

\section{Data analysis}

Immunolabeling. The relative amount of GFAP immunolabeling in NM ipsilateral and contralateral to either activity blockade or neuronal stimulation was analyzed using a BioQuant Image Analysis system (R\&M Biometrics, Nashville, TN). At least three sections per animal (or per slice) were analyzed using a $40 \times$ objective on a Leitz Aristoplan microscope. The microscopic image was relayed by a Dage MTI 68 videocamera to a video monitor. Sections were selected for measurement if they appeared evenly stained, were symmetrical in the transverse plane, and contained sufficiently central portions of NM that three nonoverlapping measurements could be taken in NM on each side of the brainstem. For each side of each section, one measurement was taken that included the medial border of NM, one that included the lateral border, and one in the center of NM. A stylus was used to designate the area to be analyzed, avoiding large blood vessels. The microdensitometry system was set up to scan the selected area of the digitized image and recognize pixels of the image whose optical density exceeded a predetermined threshold. The threshold was selected to detect intensely stained astrocytic processes. The same threshold settings were 


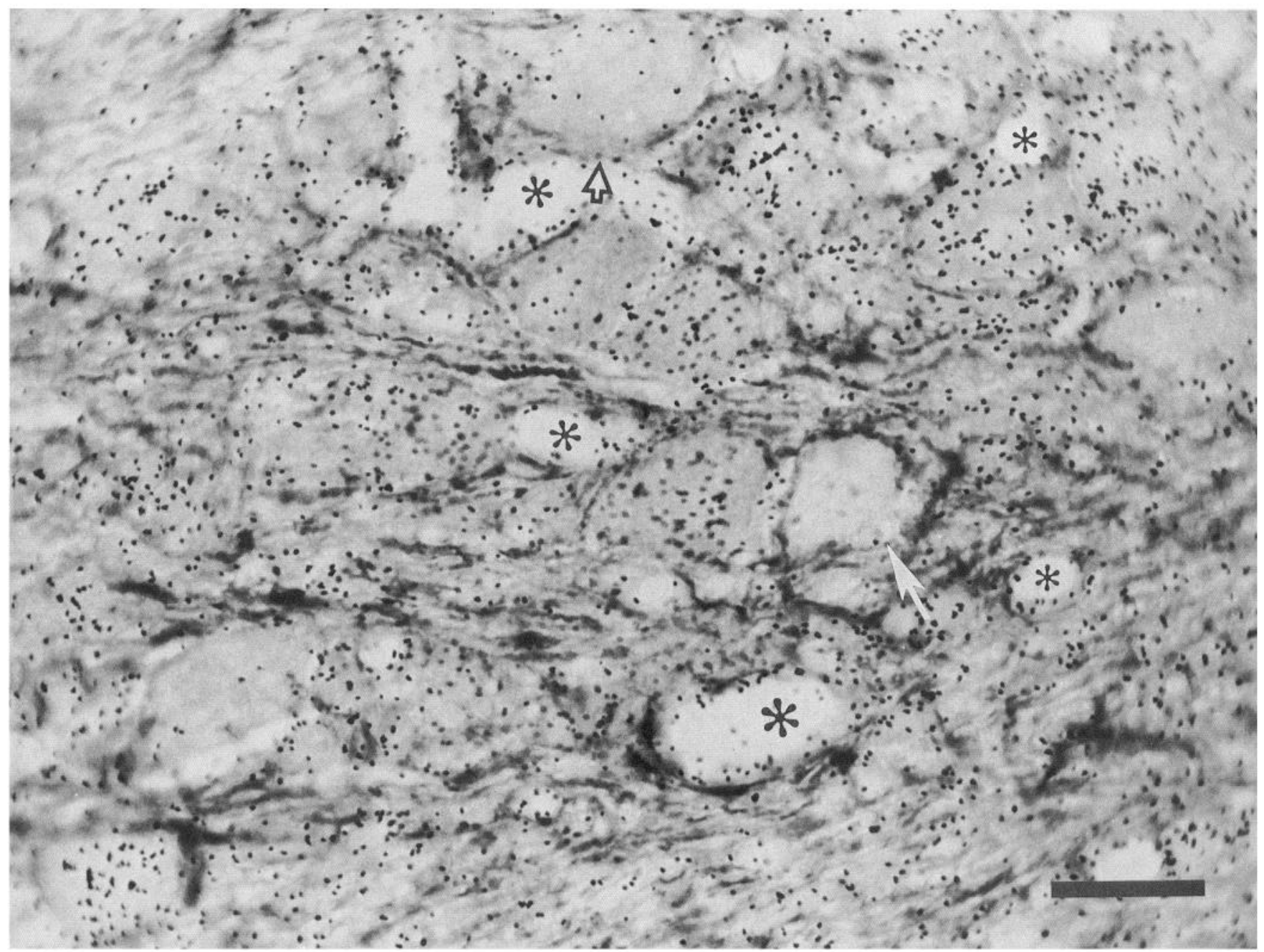

Figure 2. NM double-labeled for GFAP and ${ }^{3} \mathrm{H}$-leucine incorporation from the ipsilateral NM of a chick surviving $6 \mathrm{hr}$ following cochlea removal. Some unlabeled neurons are surrounded by GFAP-immunoreactive astrocytic processes (e.g., white arrow), while some unlabeled neurons have few GFAP-immunoreactive processes surrounding their somata (e.g., open arrow). In addition, labeled neurons surrounded by varying amounts of GFAP-immunoreactive processes can be observed throughout this photomicrograph. Asterisks mark several large and small blood vessels. Scale bar, $20 \mu \mathrm{m}$.

used for both sides of a given tissue section and usually for all sections from a given brain. The fraction of the selected area that contained GFAP-immunoreactive pixels was calculated for each of the three selected areas on each side of a tissue section. The three values for each side were then averaged providing the area-density of GFAP-immunoreactive pixels for that side of the tissue section. A ratio of the areadensity calculations for the inactive side (ipsilateral to cochlea removal or TTX treatment, or unstimulated side of slice) divided by the contralateral side of the same tissue section was then calculated. Thus, for each section, we could calculate a score for the percentage difference in GFAP-immunoreactive processes, such that a positive value reflects more GFAP-immunoreactive astrocytic processes on the inactive side of the brain [1 - (area-density in activity-deprived NM/area-density in active $\mathrm{NM}) \times 100]$. Then the three values from different sections from an animal were averaged, yielding a single value for each animal. This value represented the increase (or decrease) in GFAP-immunolabeled processes for that animal.

Double-labeled tissue. Autoradiographic exposure time was minimized so that a clear distinction could be made between ${ }^{3} \mathrm{H}$-leucinenegative ("unlabeled," fewer than 5 grains per cell) and ${ }^{3} \mathrm{H}$-leucinepositive ("labeled") neurons. Sections from the midpoint of the anteriorto-posterior axis of NM were selected for measurement using the BioQuant system. Thirty neurons were analyzed from NM of each side of each of the five brains. All neurons from a section in the middle of NM were analyzed, beginning from the medial border of the nucleus.
On the deafferented side, 10 unlabeled and 20 labeled neurons were measured. First, the neuronal perimeter, visualized using Nomarski optics, was measured. Then the length of the neuronal perimeter adjoined by GFAP-immunoreactive processes was measured. The ratio of glial-adjoined perimeter to total neuronal perimeter was averaged across all neurons of a given category (control, labeled, or unlabeled) for each of the five animals.

Electron micrographs. All of the electron micrographs from each animal were coded by a technician and then randomized. Next, the cytoplasm of the NM neuron was examined for intact ribosomes and scored using the criteria developed by Rubel et al. (1992). Neurons with normal appearing polysomes and ribosomes were scored as " 6 " and neurons with completely dissociated ribosomes were scored as " 1 ." Partial dissociation was scored as $2-5$, depending on severity. At a survival time of $6 \mathrm{hr}$, as used in the present study, virtually all cells show either completely dissociated or normal appearing ribosomes $\mathrm{Ru}-$ bel et al., 1992). In the present study, this rating system yielded unambiguous classification of every neuron on the activity-deprived side as either dissociated (" 1 ") or relatively normal ("5" or " 6 ") and every neuron on the control side as normal ("6").

The randomized micrographs were then analyzed for the amount of the soma membrane that was apposed by glial processes and that apposed by nerve terminals; the total length of soma membrane in each micrograph was measured, as was the length apposed by each of the above elements. Synaptic terminals were identified by membrane spe- 
cializations, synaptic vesicles, and numerous mitochondria. Glial processes were characterized by an undulating membrane, clear cytoplasm, and relatively few mitochondria or other organelles. Similar to the double-labeled tissue, the measure compared between groups was the percent neuronal perimeter apposed by glial processes.

Statistical tests. Statistical significance of the differences between means for all experiments measuring area-density of GFAP immunoreactivity was tested using the Mann-Whitney $U$ test. For comparisons of percentage of neuronal perimeter adjoined by glial processes, statistical significance was evaluated using a two-tailed $t$ test.

\section{Results}

\section{Double-labeled tissue}

As expected from previous studies, control neurons were all generously labeled for ${ }^{3} \mathrm{H}$-leucine and had little or no contact with GFAP-immunoreactive processes. On the deafferented side, however, most neurons, both labeled and unlabeled for ${ }^{3} \mathrm{H}$ leucine, were adjoined by GFAP-immunoreactive processes. Figure 2 shows an unlabeled neuron surrounded by GFAP immunoreactivity and unlabeled neurons with very little GFAP near their perimeter. Examples of labeled neurons with varying amounts of GFAP surrounding them also were found on the deafferented side, as shown in Figure 2. Most neurons, labeled and unlabeled, had an intermediate amount of their perimeters adjoincd by GFAP-immunorcactive processcs.

Results of the data analysis are plotted in Figure 3. The mean percentage of neuronal perimeter adjoined by GFAP-immunoreactive processes is $4.4(\mathrm{SEM}=1.5)$ for contralateral, control neurons. On the experimental side of the brain, the mean percentage of glial-adjoined perimeter is 38.1 (SEM $=5.4$ ) for labeled neurons and for unlabeled neurons it is 31.4 (SEM = 5.4). Control neurons, therefore, had reliably less of their perimeters adjoined by GFAP-immunoreactive processes than neurons on the deafferented side of the brain. This result, using a different method of analysis, replicates our previous work (Canady and Rubel, 1992; Rubel and MacDonald, 1992). The difference between the means for labeled and unlabeled neurons on the experimental side of the brain, however, does not approach statistical significance $(p>0.20)$.

In addition, there is no difference between neuronal perimeters for the threc populations. Mcan perimeters (in $\mu \mathrm{m}$ ) are $62.3(\mathrm{SEM}=0.6), 61.8(\mathrm{SEM}=0.6)$, and $60.6(\mathrm{SEM}=1.1)$ for control, labeled, and unlabeled neurons, respectively. Thus, the differences in the ratios of glial-adjoined perimeter to total perimeter are not due to differing neuronal perimeters across groups.

\section{Electron microscopy}

Measurements of NM soma membrane lengths that were adjoined by synaptic endings versus glial processes were made on four animals. The total number of neurons studied in this way was 103,63 from the deafferented side of the brain and 40 from the normally innervated side. Figure 4 shows examples of the electron micrographs from activity-deprived neurons with dissociated ribosomes, activity-deprived neurons with normal-appearing ribosomes, and control neurons from the side of the brainstem contralateral to cochlea removal. It is important to note that cochlea removal leaves the cell bodics of the cighth nerve ganglion cells intact and, at this short survival time (6 $\mathrm{hr}$ ), there is no apparent degeneration of eighth nerve axons or synaptic terminals in NM. Qualitative assessment of the soma surfaces of normal and activity-deprived NM neurons revealed clear differences. Normal neurons were characterized by asymmetrical (AS) and symmetrical (SE) (Parks, 1981) synapses cov-

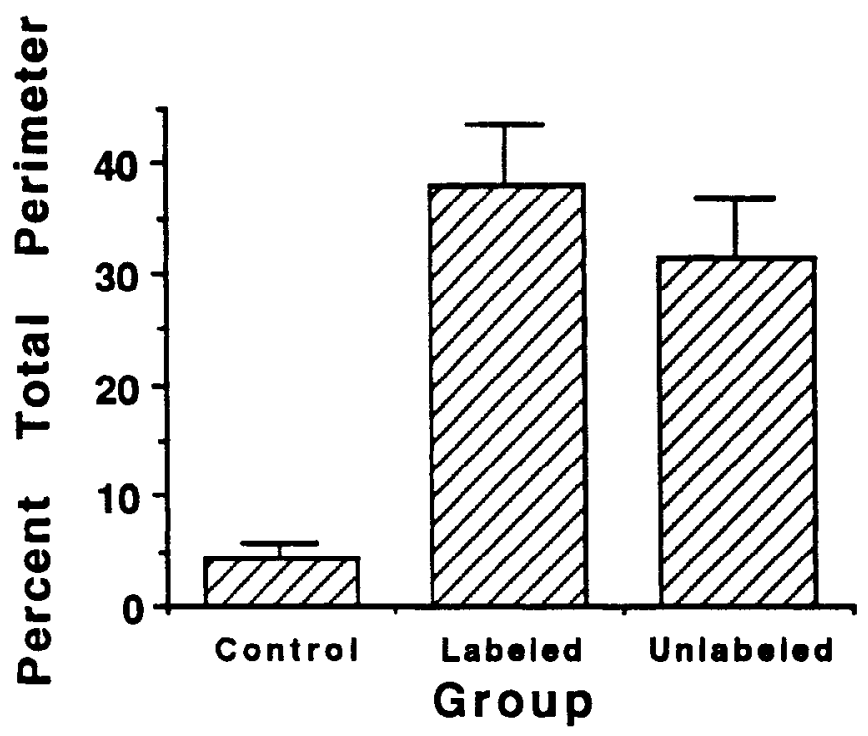

Figure 3. Percentage of neuronal perimeter adjoined by GFAP-immunoreactive processes for control neurons from the contralateral NM, and ${ }^{3} \mathrm{H}$-leucine-labeled and unlabeled neurons from the NM ipsilateral to cochlea removal. Error bars represent SEM.

ering most of the surface, the synaptic profiles interrupted by intervening glial processes. Occasionally, there were relatively long stretches of membrane $(1-2 \mu \mathrm{m})$ that were apposed by flat processes of glial cells, often having more than one layer. On the deafferented side, there was not only more neuronal surface apposed by glial processes, but it appeared as if these processes were displacing the synaptic terminals. That is, between terminal profiles the glial membrane often extended for some distance between the neuronal soma membrane and the axonal ending. In addition, the contact area between the large AS terminals and the neuronal soma was often interrupted several times along its length by a sliver or bulbous protrusion of a glial process. The ultrastructure within these glial processes was usually quite amorphous. There was an occasional mitochondrion, and often a few irregularly shaped vesicular bodies and flocculent material. There was seldom a clear network of tubules or filaments, as seen in axons. This observation suggests that the expanding glial processes do not have an abundance of polymerized intermediate filaments. While NM neurons on the activity-deprived side of the brain were easily divided into those with dissociated ribosomes versus those with intact ribosomes (Fig. 4), there were no apparent differences in synaptic profiles and glial profiles apposing the membrane surfaces of these two neuronal phenotypes.

Quantitative analyses of the neuronal membrane appositions yielded results consistent with the observations noted above. Figure 5 presents data on the mean percentage of the neuronal surface covered by glial processes for each of the four animals. In each animal, there was reliably greater surface length apposed by glial processes on the activity-deprived NM neurons than on the control ncurons from the opposite side of the same brainstem ( $p<0.01$ in all animals). This increase in the percentage of glial-apposed surface was due to both an increase in amount of glial-apposed surface $(p<0.01)$ and a decrease in amount of terminal-apposed surface $(p<0.05)$ for the activity-deprived neurons. On the other hand, comparisons of the membrane surfaces of neurons with dissociated ribosomes versus neurons 

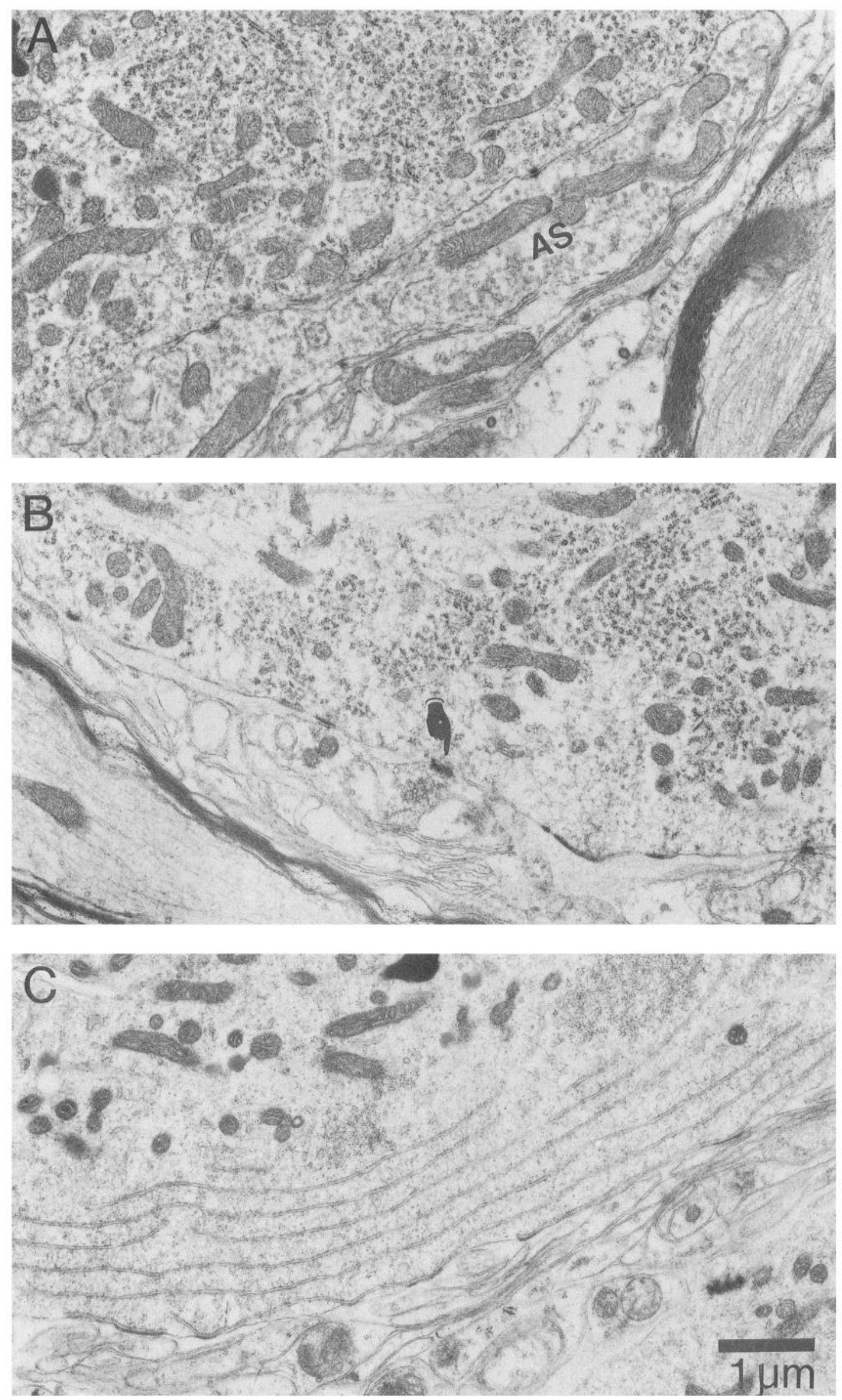


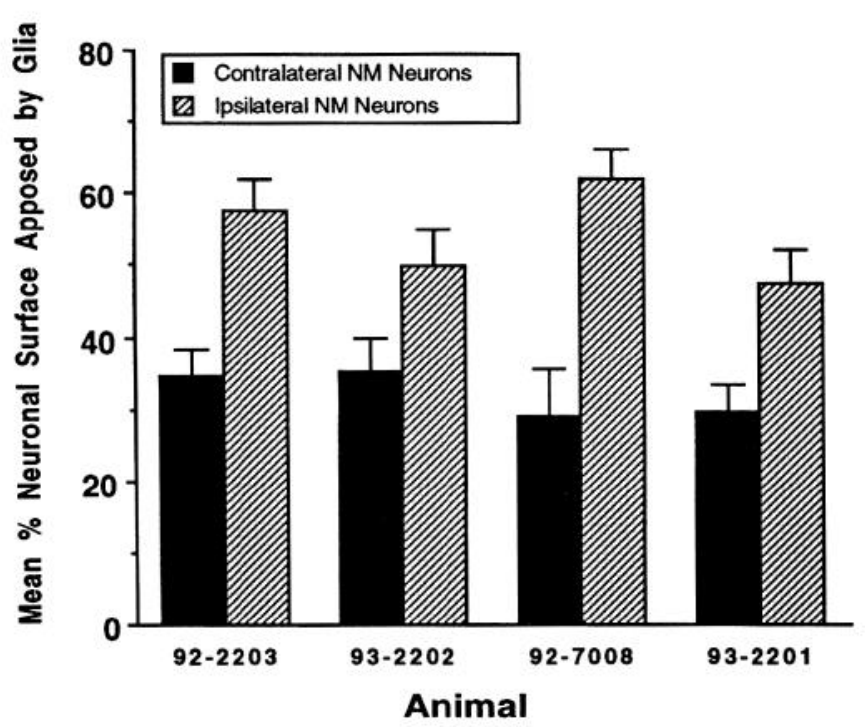

Figure 5. Mean percentage of NM neuronal surface apposed by glial processes in four experimental animals. Each set of bars shows the mean (+1 SEM) for NM neurons ipsilateral to cochlea removal (hatched bars) and on the contralateral (control) side of the brain (black bars).

with intact ribosomes from the activity-deprived side of the brain revealed no reliable differences $(p=0.41)$. None of the four animals showed reliable differences between neurons with intact versus dissociated ribosomes in any of the four measures (percentage glial apposition, percentage synaptic terminal apposition, absolute length of glial apposition, or absolute length of synaptic terminal apposition). These results are in agreement with the analyses of double-labeled neurons: there is an increase in glial processes adjoining activity-deprived neurons, but no difference between the deprived neurons undergoing cell death and those surviving the loss of excitatory input.

\section{Adult chickens}

The overall pattern and intensity of GFAP immunoreactivity in NM of the normal adult chicken brainstem is similar to that described for hatchlings (Canady and Rubel, 1992; Rubel and MacDonald, 1992). Following either cochlea removal or intralabyrinthine TTX injection in adult chickens, the experimental NM contained many more GFAP-immunoreactive processes than the control NM (Fig. 6). Results of the quantitative analysis are presented in Table 1 . The increases in GFAP immunoreactivity following TTX treatment and cochlea removal are not significantly different from each other, or from those for hatchling chicks studied after $3 \mathrm{hr}$ of activity blockade ( $p>$ $0.05)$. In all groups, the increase seen on the activity-deprived side is highly reliable.
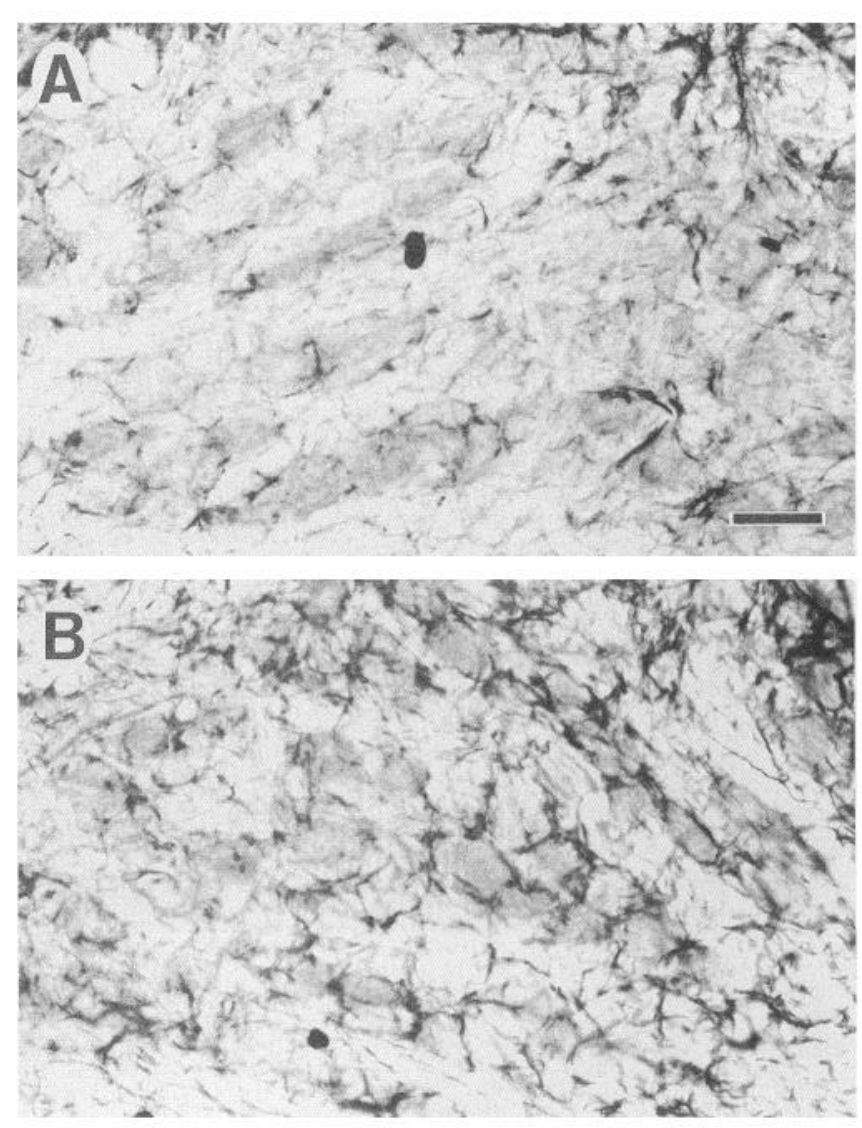

Figure 6. NM immunolabeled with an antiserum to GFAP from an adult chicken surviving $3 \mathrm{hr}$ following cochlea removal. $A$, Contralateral, control side. $B$, Ipsilateral side. Note the greater amount of GFAPimmunoreactive processes on the ipsilateral side as compared to the contralateral side. Scale bar, $30 \mu \mathrm{m}$.

\section{In vitro slices}

Electrophysiology. Figure 7 shows averaged field potentials from NM ipsilateral $(A)$ and contralateral $(D)$ to orthodromic stimulation of the auditory nerve. Unilateral stimulation evoked postsynaptic responses in NM neurons ipsilateral to the stimulated nerve, whereas no evoked activity was ever observed in NM contralateral to stimulation. When slices were maintained in low-calcium/high-magnesium ACSF, the postsynaptic response in NM was prevented. The response of the auditory nerve fibers, however, remained intact (Fig. 7B). Stimulation of NM neurons near midline resulted in an antidromically driven response recorded at the area of NM cell bodies (Fig. $7 C$ ). The magnitude of this response appeared comparable to the postsynaptic response observed after orthodromic stimulation (see also Hyson and Rubel, 1989).

\footnotetext{
Figure 4. Examples of electron micrographs from the three types of NM cell analyzed. All photomicrographs are from a single animal that received a unilateral cochlea removal and was sacrificed $6 \mathrm{hr}$ later. $A$, NM soma and adjacent type AS terminal from control side of the brain. Note continuous apposition of terminal and several sites of membrane specialization. $B$ and $C$, Both of these micrographs are from the activity-deprived side of the brain and show extensive $(B)$ or almost complete apposition $(C)$ of the neuronal membrane by glial processes. $B$, Neuron with intact ribosomes and polysomes in cytoplasm and synaptic terminal apposition (pointer) that is apparently displaced by glial processes. A second synaptic profile is seen at the extreme lower right. $C$, NM neuron with completely degraded ribosomes and polysomes. Note clusters of ribosomal breakdown debris in cytoplasm and stacks of endoplasmic reticulum, devoid of ribosomes, as described by Rubel et al. (1992). Note also the membrane specializations (thickenings) unapposed by synaptic profiles. Scale bar, $1.0 \mu \mathrm{m}$ (for all photographs).
} 
A
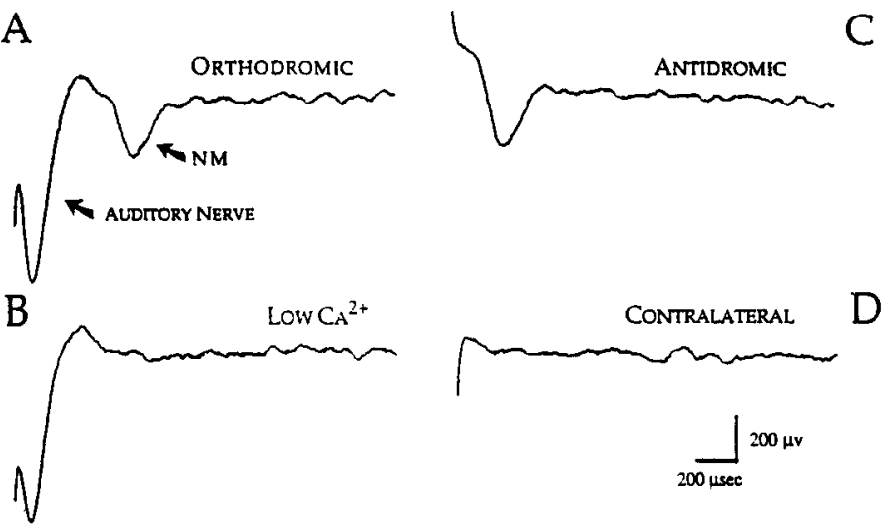

Figure 7. Representative averaged field potentials recorded in NM. $A$, The field potential recorded in NM when stimulating the ipsilateral auditory nerve shows a negative peak corresponding to the activity of the incoming auditory nerve fibers followed by a negative peak corresponding to the activity of the postsynaptic NM neurons. $B$, Recording in NM ipsilateral to stimulation of the auditory nerve in a medium containing low $\mathrm{Ca}^{2+}$ and high $\mathrm{Mg}^{2+}$ concentrations shows only the presynaptic response of auditory nerve fibers. $C$, Recording in NM after stimulation of NM axons in the crossed dorsal cochlear tract shows a negative peak corresponding to the antidromic activation of NM neurons. $D$, Recording in NM contralateral to auditory nerve stimulation reveals no evoked potential, confirming the strictly ipsilateral projection of the auditory nerve.

Note that, in vitro, the experimental manipulation is to provide electrical stimulation to otherwise inactive NM neurons. This differs from the in vivo experiments in which electrical activity is abolished by cochlea removal or TTX blockade in a spontaneously active nucleus. In both cases, we are comparing the inactive side of the brain or slice to the active side.

GFAP immunoreactivity. Unilateral stimulation of NM resulted in greater GFAP labeling on the unstimulated side of the slice. This was true whether the slice was stimulated orthodromically, orthodromically in low- $\mathrm{Ca}^{2+} / \mathrm{high}-\mathrm{Mg}^{2+}$ medium, or antidromically. Control slices that were maintained for $3 \mathrm{hr}$ without stimulation showed no consistent difference in labeling between the two sides. Figure 8 shows photomicrographs of representatives tissue sections from slices subjected to the various stimulation conditions.

These qualitative findings were confirmed by objective video image analysis of the tissue. Figure 9 shows the median percentage difference of labeling for the various groups of slices. In all cases, a positive-going bar indicates more GFAP-immunoreactive profiles on the unstimulated side of the slice. Since the difference scores of the orthodromic and antidromic control groups did not differ from cach other, the data from these two groups are combined for graphical presentation and statistical analyses. The percentage difference between the stimulated and unstimulated sides of the slice for the orthodromically stimulated slices $(n=6$, mean $=80, \mathrm{SEM}=34)$, the slices stimulated in the low- $\mathrm{Ca}^{2+} /$ high- $\mathrm{Mg}^{2+}$ medium $(n=4$, mean $=49$, SEM $=10)$, and the antidromically stimulated slices $(n=4$, mean $=$ $227, \mathrm{SEM}=102)$ were all reliably $(p<0.05)$ greater than that of the combined control groups $(n=10$, mean $=-1.7, \mathrm{SEM}=$ 18).

\section{Discussion}

Although both neurons and astrocytes in NM are rapidly modified by afferent activity blockade, the present study shows that
Table 1. Changes in NM GFAP immunoreactivity following $3 \mathrm{hr}$ of unilateral eighth nerve activity blockade in adult chickens and hatchlings.

\begin{tabular}{lll} 
Treatment & $\begin{array}{l}\text { Number of } \\
\text { chickens }\end{array}$ & Change in GFAP \\
\hline CR (Adult) & 3 & $+212 \%(34)$ \\
TTX (Adult) & 6 & $+154 \%(64)$ \\
TTX (Hatchling) & 5 & $+177 \%(25)$
\end{tabular}

Change in GFAP represents mean increase in area density of GFAP-immunoreactive processes in the NM ipsilateral to cochlea removal (CR) or TTX injection as compared to the contralateral NM. SEMs are in parentheses.

the signals initiating these two responses do not appear to be related: the positioning of GFAP-immunoreactive processes bears no relationship to the positioning of neurons that will die or survive following activity blockade; the neuronal response is dependent on both age of the animal and synaptic transmission, whereas the astrocytic response depends on neither. These different response patterns to activity deprivation indicate that either neurons and glia are regulated by different activity-dependent signals, or the two cell types have different sensitivities to the same signals. While these results suggest independence of the initial neuronal and glial responses to activity blockade, it is important to note that the two responses may still influence one another. This initial independence does not necessarily mean that a long-term causal relationship between the neuronal and glial responses to activity blockade does not exist.

The term "reactive glial processes" refers to astrocytic processes containing increased amounts of the intermediate filament protein GFAP. Reactive processes are identifiable at the light microscopic level by their immunoreactivity for this astrocyte-specific intermediate filament protein. These processes are often increased in areas of neural injury (Lindsay, 1986; Malhotra et al., 1990). In some (but not all) examples of reactive gliosis, mitotic activity of astrocytes or astrocyte precursor cells is evident (Janeczko, 1988; Miyake et al., 1988; Topp et al., 1989). For the purposes of this report, we will use the term "glial response" to refer to the increased GFAP immunoreactivity induced by the experimental manipulations of neuronal activity. This does not imply that all reactive glial processes are the same. In the present study, we have examined glial responses immediately following the manipulation, before anatomical evidence of eighth nerve degeneration (Parks and Rubel, 1978). Much more dramatic glial changes occur in NM at 2-3 d after cochlea removal, including a fivefold increase in GFAP immunoreactivity (Rubel and MacDonald, 1992), proliferation of glial cell precursors (Lurie and Rubel, 1994), and an increase in GFAP mRNA (Biavati and Steward, 1992).

\section{Double-labeled tissue and electron microscopy}

The double-label experiment and EM observations take advantage of a system in which deafferentation, or afferent activity blockade, is known to result in rapid changes in both the neurons and the glial cells. By $6 \mathrm{hr}$ after afferent activity deprivation, the subset of neurons destined to die can be identified by cessation of protein synthesis (Steward and Rubel, 1985), degradation of ribosomes (Rubel et al., 1992), and loss of immunoreactivity for an antibody directed against ribosomal RNA (Garden et al., 1994). This provides a unique opportunity to examine the relationship between reactive glial processes and neurons destined to die. 

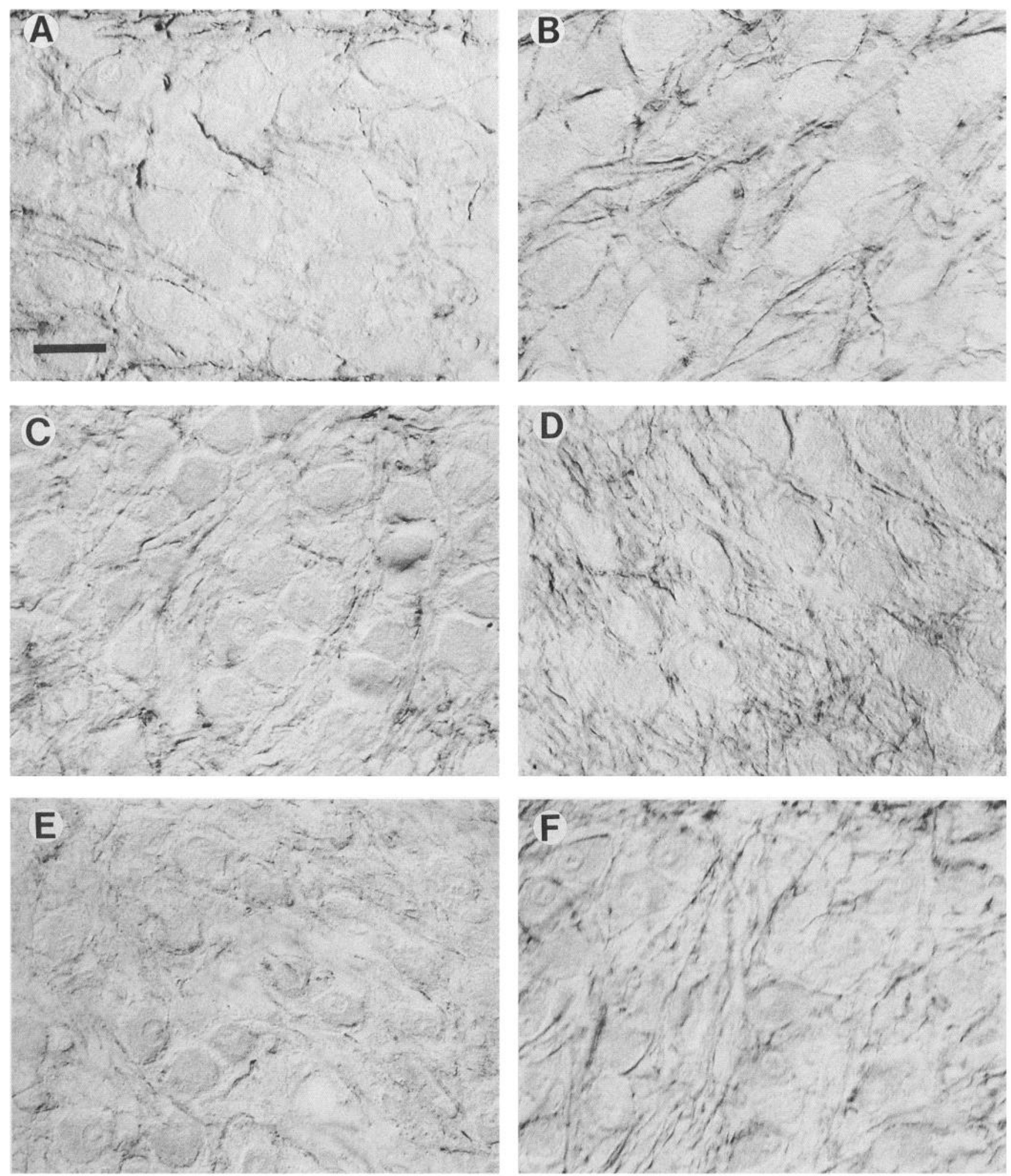

Figure 8. Representative micrographs from slices immunostained for GFAP after different stimulation conditions. Dark immunopositive processes surround the unstained NM neurons. $A, C$, and $E$ are pictures of NM on the stimulated side of the slices, while $B, D$, and $F$ are pictures from the same tissue sections, but from NM on the unstimulated side of the slices. Stimulation conditions: $A$ and $B$, Orthodromic stimulation. $C$ and $D$, Orthodromic stimulation in low $\mathrm{Ca}^{2+} /$ high $\mathrm{Mg}^{2+}$ medium. $E$ and $F$, Antidromic stimulation. Scale bar (in $A$ ), $25 \mu \mathrm{m}$ (for all photomicrographs). 


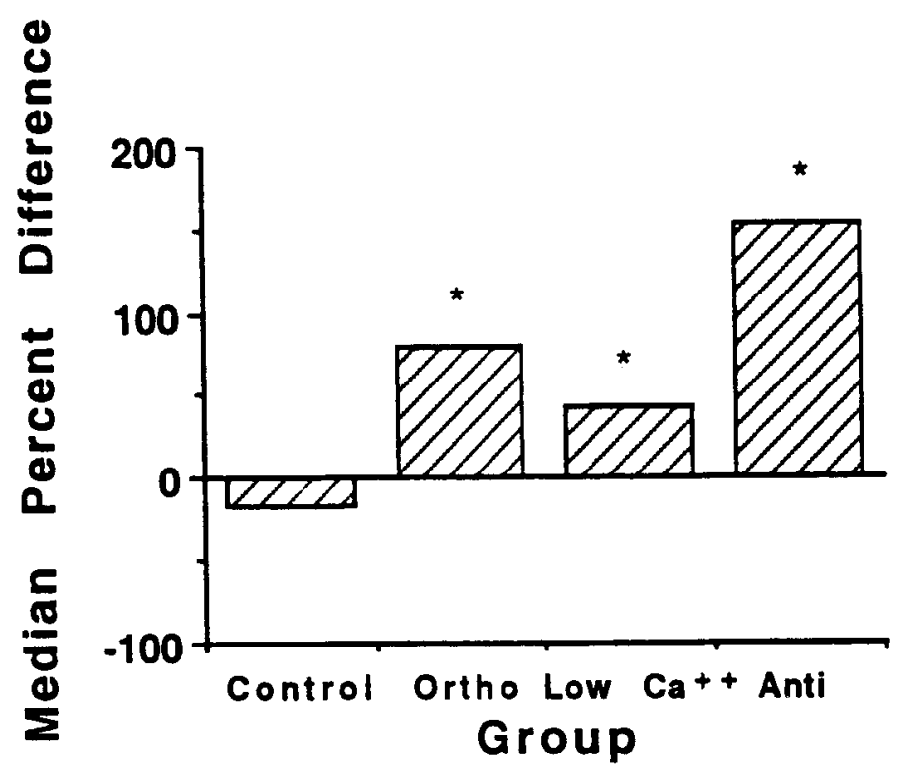

Figure 9. Median percentage difference in labeling between the unstimulated and stimulated sides of the slice after the various stimulation conditions. Percentage difference is calculated as $100 \times$ (unstimulated/ stimulated - 1); thus, positive numbers indicate that the unstimulated side of the slice showed greater immunostaining than the stimulated side. Asterisks indicate that the difference score is reliably greater than that of the control group $(p<0.05)$. Ortho, unilateral orthodromic stimulation; $\mathrm{Low} \mathrm{Ca}^{++}$, unilateral orthodromic stimulation in low-Ca ${ }^{2+}$ high- $\mathrm{Mg}^{2+}$ medium; $A n t i$, unilateral antidromic stimulation.

Measurements of both GFAP-immunoreactive processes adjoining NM neuronal perikarya (light microscopy) and glial processes apposed to the soma membrane (electron microscopy) support our earlier observations of marked increases in glial processes when eighth nerve activity is suppressed for as little as 3-6 hr. Neither type of measurement, however, revealed any difference in the glial response associated with apoptotic-appearing neurons versus neurons with normal amino acid incorporation and normal-appearing ribosomes on the activity-deprived side of NM. Both of these results are consistent with the hypothesis that the glial and neuronal responses to afferent activity blockade are independent of each other. This similarity of outcomes occurs despite differences in the methods of measuring the extent of glial process apposition to neuronal perikarya. At the EM level, we measured the extent of apposition by any glial process, without regard to GFAP immunoreactivity. At the light microscopic level, our analysis was restricted to GFAP-immunopositive processes. In addition, light microscopic resolution does not reveal the thin glial lamellae that adjoin the neuronal perikaryon and interdigitate with synaptic profiles. These differences likely account for the reduced percentage of perimeter apposed by glial processes measured in the control neurons of the light microscopic study $(4.4 \%)$ as compared to the EM study (32\%).

While one cannot prove the null hypothesis, the results presented here lend strong support for it. In addition to the similarity of the mean ratios of glial processes to total neuronal perimeter between ${ }^{3} \mathrm{H}$-leucine-labeled and unlabeled neurons, the variability of these measures were similar. In both cases, the standard deviation was 0.121 . Examination of variability in the EM measurements also yielded very similar standard deviations for intact and apoptotic neurons in the deprived NM.
If there were a trend toward a preferential distribution of glial processes around one of the two populations of deafferented neurons, we might expect to see greater variability of ratios for that population.

\section{Adult chickens}

Unlike the neuronal response to activity blockade, the glial response is seen in both young and mature chickens and is at least as dramatic in adults. These results also are consistent with the hypothesis that the initial glial and neuronal responses to activity blockade are independent. This independence implies that different extrinsic signals are regulating NM neurons and astrocytes or that the initial responses of neurons and astrocytes to activity-related signals are independent. As noted above, it is still possible that the glial response observed in adults is causally related to reduced neuronal death. Conversely, mature neurons may be more responsive to any bencficial cffects of GFAPimmunoreactive processes than young neurons.

\section{In vitro slices}

In addition to the independence of neuronal and glial responses to afferent activity blockade, there is also evidence for independence of the mechanisms by which afferent activity influences neurons and glia in NM. Previous in vilro studies have shown that the maintenance of neuronal protein synthesis requires synaptic transmission (Hyson and Rubel, 1989), while here we show that the regulation of astrocytic GFAP immunoreactivity does not.

Orthodromic stimulation of NM suppresses GFAP immunostaining in vitro, just as observed in vivo, indicating that the in vitro slice is an adequate preparation for examining possible signals that are responsible for glial regulation. In contrast with the neuronal sensitivity to the mode of stimulation, however, the glial cells responded to all three types of in vitro stimulation. Electrical stimulation of the auditory nerve resulted in less GFAP immunostaining on the stimulated side of the slice even when synaptic transmission from the auditory nerve to NM neurons was blocked by maintaining the slice in a medium containing low $\mathrm{Ca}^{2+}$ and high $\mathrm{Mg}^{2+}$ concentrations. Antidromic stimulation had a similar effect. Two conclusions can be drawn from these results: (1) electrical activity of the postsynaptic NM neuron and/or recurrent afferents subsequent to NM activation is not necessary for the suppression of GFAP immunoreactivity in NM, and (2) calcium-dependent release of neurotransmitter or some associated trophic substance is not required for this type of regulation.

\section{Possible signals for glial regulation in the brainstem auditory system}

The precise signals from active auditory neurons that are responsible for the regulation of astrocytic structure are still unknown. The present experiments do narrow the range of likely candidates. One hypothesis is that changes in neurotransmitter release could regulate astrocytic structure. Several studies have shown that activation of neurotransmitter receptors results in the phosphorylation of GFAP (McCarthy et al., 1985, 1988; Lauder and McCarthy, 1986) and induction of a more processbearing phenotype in cultured astrocytes (Narumi et al., 1978; Shain et al., 1987; Bicknell et al., 1989). A similar role for neurotransmitters, neuromodulators, or neurotrophic agents in the activity-dependent suppression of glial processes in NM, however, appears to be unlikely. First, a decrease in neuronal 
activity, which would presumably result in decreased release of neuroactive (or glioactive) substances, results in a rapid increase in GFAP immunostaining, glial process length (Rubel and MacDonald, 1992), and glial process apposition to NM neurons. Second, blockade of calcium-dependent release by maintaining the slice in low-Ca ${ }^{2+} /$ high- $\mathrm{Mg}^{2+}$ medium did not prevent the activity-dependent suppression of GFAP immunoreactivity. Thus, if molecules released from the nerve endings are responsible for the regulation of glial structure in NM, their effects on astrocytic structure is opposite to results previously reported for cultured astrocytes. Furthermore, their release must be activity dependent, but not requiring $\mathrm{Ca}^{2+}$-dependent synaptic mechanisms.

Other studies are in agreement with our general results, finding an inverse relationship between GFAP immunoreactivity (and glial process growth) and synaptic activity, but suggest that calcium-dependent release of a neurotransmitter or an associated neuromodulator is involved. For example, an elegant series of studies by Hatton and colleagues (e.g., see Tweedle and Hatton, 1980; Salm et al., 1982, 1985; Perlmutter et al., 1984; Hatton, 1988; Smithson et al., 1990) has shown in vivo and in vitro that conditions associated with increased synaptic activity result in rapid downregulation of GFAP immunoreactivity and retraction of processes by pituicytes. Studies by Bicknell et al. (1989) and Smithson et al. (1990) implicate transmitter release as an important signal in this system by showing that $\beta$-adrenergic agonists induce rapid morphological changes in pituicytes. Recently, Georgiou et al. (1993) reported a rapid increase in GFAP immunoreactivity by Schwann cells at the neuromuscular junction when activity was eliminated by nerve transection. Stimulation of the nerve trunk prevented this upregulation of GFAP expression. In contrast to the results reported here, however, blockade of neurotransmitter release by conotoxin reversed the effects of stimulation. These authors conclude that transmitter release suppresses GFAP upregulation.

An alternative category of possible signals regulating glial cell structure in NM is activity-dependent alterations in the local ionic environment. Neuronal activity has been shown to influence the extracellular concentration of several ions (Nicholson et al., 1978; Urbanics et al., 1978; Somjen, 1979; Walton and Chesler, 1988; Jarolimek et al., 1989; Jendelová and Syková, 1991). For example, high levels of neuronal activity increase the extracellular concentration of $\mathrm{K}^{+}$(Nicholson et al., 1978; Urbanics et al., 1978; Somjen, 1979; Walton and Chesler, 1988; Jendelová and Syková, 1991). Correspondingly, increases in extracellular $\mathrm{K}^{+}$concentration within the physiological range, have been shown to decrease GFAP content in cultured astrocytes obtained from the chick brainstem (Canady et al., 1990). Thus, local neuronal activity, by maintaining relatively high levels of extracellular $\mathrm{K}^{+}$, could result in relatively low levels of GFAP and suppression of process growth by astrocytes.

The results of the experiments reported here, as well as our earlier experiments on activity-dependent regulation of GFAP immunoreactivity (Canady and Rubel, 1992; Rubel and MacDonald, 1992), are consistent with the hypothesis that elevated levels of extracellular $\mathrm{K}^{+}$suppress astrocyte growth and GFAP expression. In vivo, the auditory system maintains a tonically high level of neuronal activity with spontaneous activity of single NM neurons frequently reaching as high as $100 \mathrm{~Hz}$ (Warchol and Dallos, 1990). Increases in extracellular $\mathrm{K}^{+}$concentration have been observed at much lower stimulation rates in a variety of preparations (Nicholson et al., 1978; Urbanics et al., 1978;
Walton and Chesler, 1988; Jarolimek et al., 1989; Jendelová and Syková, 1991). Cochlea removal or injection of TTX into the inner ear eliminates this relatively high level of activity (Born et al., 1991), and could thereby cause a chronic reduction in the local extracellular $\mathrm{K}^{+}$concentration. Although we have focused on a possible role of local $\mathrm{K}^{+}$concentration, it is important to recognize that activity-dependent changes in the concentrations of other ions may be important signals for regulating glial cell structure. For example, neuronal activity also influences local concentrations of $\mathrm{Ca}^{2+}$ and $\mathrm{H}^{+}$(Nicholson et al., 1978).

While altered ionic concentrations or transmitter release may provide the extracellular signal by which neuronal activity influences astrocytic structure, secondary changes in the astrocyte's intracellular environment must be responsible for the regulation of GFAP expression and the growth or retraction of processes. At this time, there is little information on the intracellular mechanisms regulating glial cell shape. One mechanism could be the upregulation of mRNA. Steward and colleagues have shown that increases in neuronal activity in the rat hippocampus cause an upregulation of GFAP mRNA (Steward et al., 1990, 1991). In contrast, a different mechanism appears responsible for the activity-dependent upregulation of GFAP seen in the chick brainstem. Biavati and Steward (1992) report that a measurable increase in GFAP mRNA is not seen until $60 \mathrm{hr}$ after cochlea removal, a time corresponding with massive degeneration of eighth nerve axons and with glial proliferation (Lurie and Rubel, 1994).

\section{Conclusion}

Astrocytic proliferative responses have been reported to occur under a number of neuropathological conditions (Lindsay, 1986; Malhotra et al, 1990). Such instances of reactive gliosis could be the result of alterations of neuronal activity concomitant with the pathology, or the result of a large number of other sequelae to injury and degeneration. In fact, only rarely have alterations in GFAP been observed prior to a day or two after the experimental treatment (Amaducci et al., 1981; Björklund et al., 1986; Petito et al., 1990). This suggests that signals other than those associated with neuronal activity play a dominant role in these injury reactions. This suggestion seems to be born out by recent studies of glial proliferation following deafferentation in the chick auditory system (Lurie and Rubel, 1994). While the increase in GFAP immunoreactivity and astrocytic process growth occurs within 3-6 hr after cochlea removal, proliferation of astrocytes following cochlea removal is not evident until $36-48 \mathrm{hr}$. Interestingly, this time corresponds with the appearance of large amounts of degenerative debris from the breakdown of eighth nerve axons.

Examples of glial reactions under nonpathological conditions are exceedingly rare. One notable exception is in the supraoptic nucleus of rats (discussed above), where astrocytes undergo reversible morphological changes under conditions of lactation and dehydration (Salm et al., 1985; Hatton, 1990). Specifically, during lactation there is a reduction of GFAP immunostaining within this nucleus. Lactation is known to increase the release of oxytocin from hypothalamic neurons and these neurons show bursts of electrical activity prior to oxytocin release (Wakerley and Lincoln, 1973). Thus, the results of Salm et al. (1985) are consistent with the hypothesis that local neuronal activity downregulates GFAP immunoreactivity, causing retraction of processes and thereby facilitating synchronous activity of hormonereleasing neurons (Hatton et al., 1984). The electron microscopic 
observations reported here, along with dynamic properties of GFAP expression reported by Canady and Rubel (1992), suggest that a similar interaction between neurons and glia may be occurring in the chick auditory pathways. It is tempting to speculate that changes in activity within a variety of neural systems are capable of altering the efficacy of synaptic transmission by dynamically regulating the growth and retraction of glial processes at specific synaptic terminals.

\section{References}

Amaducci L, Forno KI, Eng LF (1981) Glial fibrillary acidic protein in cryogenic lesions of the rat brain. Neurosci Lett 21:27-32.

Ballanyi K, Grafe P, ten Bruggencate G (1987) Ion activities and potassium uptake mechanisms of glial cells in guinea-pig olfactory cortex slices. J Physiol (Lond) 382:159-174.

Banker GA (1980) Trophic interactions between astroglial cells and hippocampal neurons in culture. Science 209:809-810.

Biavati MJ, Steward O (1992) Expression of glial fibrillary acidic mRNA during transneuronal degeneration in chick nucleus magnocellularis. Assoc Res Otolaryngol Abstr February 2-6:55.

Bicknell RJ, Luckman SM, Inenaga K, Mason WT, Hatton GI (1989) $\beta$-Adrenergic and opioid receptors on pituicytes cultured from adult rat neurohypophysis: regulation of cell morphology. Brain Res Bull 22:379-388.

Björklund H, Olson L, Dahl D, Schwarcz R (1986) Short- and longterm consequences of intracranial injections of the excitotoxin, quinolinic acid, as evidenced by GFA immunohistochemistry of astrocytes. Brain Res 271:267-277.

Born DE, Rubel EW (1985) Afferent influences on brain stem auditory nuclei of the chicken: neuron number and size following cochlea removal. J Comp Neurol 231:435-445.

Born DE, Rubel EW (1988) Afferent influences on brain stem auditory nuclei of the chicken: presynaptic action potentials regulate protein synthesis in nucleus magnocellularis. J Neurosci 8:901-919.

Born DE, Durham D, Rubel EW (1991) Afferent influences on brainstem auditory nuclei of the chick: nucleus magnocellularis neuronal activity following cochlea removal. Brain Res 557:37-47.

Brenneman DE, Neale EA, Foster GA, d'Autremont SW, Westbrook GL (1987) Nonneuronal cells mediate neurotrophic action of vasoactive intestinal peptide. J Cell Biol 104:1603-1610.

Canady KS, Rubel EW (1992) Rapid and reversible astrocytic reaction to afferent activity blockade in chick cochlear nucleus. J Neurosci 12: 1001-1009.

Canady KS, Ali-Osman F, Rubel EW (1990) Extracellular potassium influences DNA and protein synthesis and glial fibrillary acidic protein expression in cultured glial cells. Glia 3:368-374.

Canady KS, Olavarria JF, Rubel EW (1992) Rapid increase in astrocytic GFAP immunoreactivity in LGN of enucleated rats. Soc Neurosci Abstr 18:1310.

Choi DW (1988) Glutamate neurotoxicity and diseases of the nervous system. Neuron 1:623-634.

Clarke, PGH (1990) Developmental cell death: morphological diversity and multiple mechanisms. Anat Embryol (Berl) 181:195-213.

Garden GA, Canady KS, Lurie DI, Bothwell M, Kubel EW (1994) A biphasic change in ribosomal conformation during transneuronal degeneration is altered by inhibition of mitochondrial, but not cytoplasmic protein synthesis. J Neurosci 14:1994-2008.

Georgiou J, Robitaille R, Charlton MP (1993) Schwann cell GFAP regulated by transmitter release. Soc Neurosci Abstr 19:418

Globus A (1975) Brain morphology as a function of presynaptic morphology and activity. In: The developmental neuropsychology of sensory deprivation (Riesen AH, ed), pp 9-91. Ncw York: Academic.

Hatton GI (1988) Cellular reorganization in neuroendocrine secretion. In: Stimulus-secretion coupling in neuroendocrine systems (Ganten D, Pfaff D, Pickering B, eds), pp 1-27, Berlin: Springer.

Hatton GI (1990) Emerging concepts of structure-function dynamics in adult brain: the hypothalamo-neurohypophysial system. Prog Neurobiol 34:437-504.

Hatton GI, Perlmutter LS, Salm AK, Tweedle CD (1984) Dynamic neuronal-glial interactions in hypothalamus and pituitary: implications for control of hormone synthesis and release. Peptides 5:121138.
Hawrylak N, Chang FL, Greenough WT (1993) Astrocytic and synaptic response to kindling in hippocampal subfield CAl. II. Synaptogenesis and astrocytic process increases to in vivo kindling. Brain Res 603:309-316.

Hyson RL, Rubel EW (1989) Transneuronal regulation of protein synthesis in the brain stem auditory system of the chick requires synaptic activation. J Neurosci 9:2835-2845.

Janeczko K (1988) The proliferative response of astrocytes to injury in neonatal rat brain. A combined immunocytochemical and autoradiographic study. Brain Res 456:280-285.

Jarolimek W, Misgeld U, Lux HD (1989) Activity dependent alkaline and acid transients in guinea pig hippocampal slices. Brain Res 505: 225-232.

Jendelová $\mathrm{P}$, Syková $\mathrm{E}$ (1991) Role of glia in $\mathrm{K}^{+}$and $\mathrm{pH}$ homeostasis in the neonatal rat spinal cord. Glia 4:56-63.

Lauder J, McCarthy K (1986) Neuron-glial interactions. In: Astrocytes, Vol 2 (Fedoroff S, Vernadakis A, eds), pp 295-314. Orlando, FL: Academic.

Lindsay RM (1986) Reactive gliosis. In: Astrocytes, Vol 3 (Fedoroff S, Vernadakis A, eds), pp 231-262. Orlando, FI: Academic.

Lurie DI, Rubel EW (1994) Astrocyte proliferation in the chick auditory brainstem following cochlea removal. J Comp Neurol, in press.

Malhotra SK, Shnitka JK, Elbrink J (1990) Reactive astrocytes-a review. Cytobios 61:133-160.

Manthorpe M, Rudge JS, Varon S (1986) Astroglial cell contributions to neuronal survival and neuritic growth. In: Astrocytes, Vol 2 (Federoff S, Vernadakis A, eds), pp 315-376. Orlando, FL: Academic.

McCarthy KD, Prime J, Harmon T, Pollenz R (1985) Receptor-mediated phosphorylation of astroglia intermediate filament proteins in cultured astroglia. J Neurochem 44:723-730.

McCarthy KD, Salm A, Lerea LS (1988) Astroglial receptors and their regulation of intermediate filament protein phosphorylation. In: Glial cell receptors (Kimelberg HK, ed), pp 1-22. New York: Raven.

McDonald JW, Johnston MV (1990) Physiological and pathophysiological roles of excitatory amino acids during central nervous system development. Brain Res Rev 15:41-70.

Meshul CK, Frederick JS, Herndon RM (1987) Astrocytes play a role in regulation of synaptic density. Brain Res 402:139-145.

Miyake T, Hattori T, Fukuda M, Kitamura T, Fujita S (1988) Quantitative studies on proliferative changes of reactive astrocytes in mouse cerebral cortex. Brain Res 451:133-138.

Narumi S, Kimelberg HK, Bourke RS (1978) Effects of norepinephrine on the morphology and some enzyme activities of primary monolayer cultures from rat brain. J Neurochem 31:1479-1490.

Nicholson C, ten Bruggencate G, Stöckle H, Steinberg R (1978) Calcium and potassium changes in extracellular microenvironment of cat cerebellar cortex. J Neurophysiol 41:1026-1039.

Parks TN (1981) Morphology of axosomatic endings in an avian cochlear nucleus: nucleus magnocellularis of the chicken. J Comp Neurol 203:425-440.

Parks TN, Rubcl EW (1978) Organization and development of the brain stem auditory nuclei of the chicken: primary afferent projections. J Comp Neurol 180:439-448.

Perlmutter LS, Hatton GI, Tweedle CD (1984) Plasticity in the neurohypophysis in vitro: effects of osmotic changes in pituicytes. Neuroscience 12:503-511.

Petito CK, Morgello S, Felix JC, Lesser ML (1990) The two patterns of reactive astrocytosis in postischemic rat brain. J Cereb Blood Flow Metab 10:850-859.

Reh TA, Constantine-Paton M (1985) Eye-specific segregation requires neural activity in three-eyed Rana pipiens. J Neurosci 5:11321143.

Reier PJ (1986) Gliosis following CNS injury: the anatomy of astrocytic scars and their influences on axonal elongation. In: Astrocytes, Vol 3 (Fedoroff S, Vernadakis A, cds), pp 263-324. Orlando, FL: Academic.

Rothman SM, Olney JW (1987) Excitotoxicity and the NMDA receptor. Trends Neurosci 10:299-302.

Rubel EW, MacDonald GH (1992) Rapid growth of astrocytic processes in $\mathrm{n}$. magnocellularis following cochlea removal. J Comp Neurol 318:415-425.

Rubel EW, Hyson RL, Durham D (1990) Afferent regulation of neurons in the brain stem auditory system. J Neurobiol 21:169-196.

Rubel EW, Falk PM, Canady KS, Steward O (1992) A cellular mechanism underlying activity-dependent transneuronal degeneration: rapid 
but reversible destruction of neuronal ribosomes. Brain Dysfunct 4:5574.

Salm AK, Hatton GI, Nilaver G (1982) Immunoreactive glial fibrillary acidic protein in pituicytes of the rat neurohypophysis. Brain Res 236: $471-476$.

Salm AK, Smithson KG, Hatton GI (1985) Lactation-associatcd rcdistribution of the glial fibrillary acidic protein within the supraoptic nucleus. Cell Tissue Res 242:9-15.

Shain W, Forman DS, Madelian V, Turner JN (1987) Morphology of astroglial cells is controlled by beta-adrenergic receptors. J Cell Biol 105:2307-2314.

Smithson KG, Suarez I, Hatton GI (1990) Beta-adrenergic stimulation decreases glial and increases neural contact with the basal lamina in rat neurointermediate lobes incubated in vitro. $\mathrm{J}$ Neuroendocrinol 2:693-699.

Somjen GG (1979) Extracellular potassium in the mammalian central nervous system. Annu Rev Physiol 41:159-177.

Steward O, Rubel EW (1985) Afferent influences on brain stem auditory nuclei of the chicken: cessation of amino acid incorporation as an antecedent to age-dependent transncuronal degeneration. J Comp Neurol 231:385-395.

Steward O, Torre ER, Phillips LL, Trimmer PA (1990) The process of reinnervation in the dentate gyrus of adult rats: time course of increases in mRNA for glial fibrillary acidic protein. J Neurosci 10: 2373-2384.

Steward O, Torre ER, Tomasulo R, Lothman E (1991) Neuronal activity up-regulates astroglial gene expression. Proc Natl Acad Sci USA 88:6819-6823.
Stryker MP, Harris WA (1986) Binocular impulse blockade prevents the formation of ocular columns in cat visual cortex. J Neurosci 6:2117-2133.

Topp KS, Faddis BT, Vijayan VK (1989) Trauma-induced proliferation of astrocytes in the brains of young and aged rats. Glia 2:201211.

Tweedle CD, Hatton GI (1980) Evidence for dynamic interactions between pituicytes and neurosecretory axons in the rat. Neuroscience 5:661-667.

Urbanics R, Leniger-Follert E, Lübbers DW (1978) Time course of changes of extracellular $\mathrm{H}^{+}$and $\mathrm{K}^{+}$activities during and after direct electrical stimulation of the brain cortex. Pfluegers Arch 378:47-53.

Wakerley JB, Lincoln DW (1973) The milk ejection reflex of the rat: a 20-/to 40-fold acceleration in the firing of paraventricular neurones during oxytocin release. J Endocrinol 57:477-493.

Walton KD, Chesler M (1988) Activity-related extracellular potassium transients in the neonatal rat spinal cord: an in vitro study. Neuroscience 25:983-995.

Walz W, Hertz L (1983) Intracellular ion changes of astrocytes in response to extracellular potassium. J Neurosci Res 10:411-423.

Warchol ME, Dallos P (1990) Neural coding in the chick cochlear nucleus. J Comp Physiol [A] 165:721-734.

Wong-Riley MTT (1972) Terminal degeneration and glial reactions in the lateral geniculate nucleus of the squirrel monkey after eye removal. J Comp Neurol 144:61-92. 